
numerosos libros y artículos entre los que destacamos La narrativa de Miguel Ángel Asturias (1966), Quevedo y la poesía hispanoamericana del siglo XX (1976), De tiranos, héroes y brujos (1982), Mundo

\title{
VIAJE AL CORAZÓN DE NERUDA
} mágico y mundo real. La narrativa de Miguel Ángel Asturias (1999). Es autor de la Nueva historia de la literatura hispanoamericana (1997), así como de varios trabajos sobre Pablo Neruda del que tradujo en Italia varias obras. Dirige varias revistas y colecciones latinoamericanistas.

GIUSEPPE BELLINI

Como es bien sabido, la obra literaria puede ser sometida a una variedad de enfoques críticos, según la orientación de quien la examina, pero siempre habrá que prestar atención a lo que el autor ha querido comunicar al lector, o sea, a lo que dimana de su experiencia vivencial y de sus convicciones, al mensaje que quiere expresar.

Existe, sin embargo, un problema que el lector resuelve rápidamente, no más asomarse a una obra, sobre todo si es de índole poética: decidir si lo que está leyendo tiene interés para él, si corresponde a sus orientaciones o si las contrasta y en todo caso si la lectura, por más encontradas que sean las orientaciones, despierta en él esa curiosidad intelectual que le lleva a proseguirla y al fin y al cabo si se transforma en un ejercicio agradable.

Solamente así se explica cómo tanto libro enriquece las bibliotecas, sin más páginas cortadas que las iniciales. La biblioteca personal de uno, por más tomos que reúna, siempre tendrá un rincón apartado o islas diseminadas, donde están los libros que realmente le han hablado y le siguen hablando a su dueño, porque se han grabado profundamente en su intimidad, le han permitido penetrar la condición de su autor y al mismo tiempo le han ayudado a comprender la suya propia y la del mundo que le rodea.

A partir de Amado Alonso ${ }^{1}$, benemérito intérprete de las Residencias, la obra poética de Pablo Neruda ha tenido infinitos exégetas, traductores e intérpretes, entre los cuales, a la fuerza, por méritos o deméritos, tengo que ponerme yo mismo, para luego explicar mi acercamiento a la poesía del autor chileno y cómo la he ido sintiendo y presentando a través de todos estos años.
Tengo que hacer una premisa: soy un lector que entiende la creación literaria no solamente como un ejercicio de estilo, sino como comunicación de esa sustancia impalpable que hace vibrar íntimamente a quien lee, le abre el sugestivo camino, entre afirmaciones, contradicciones y aciertos, hacia la región más íntima del autor, le hace partícipe de una «historia» humana, recatada y revelada con pudor y en la que se concreta la condición del hombre en la tierra.

Así he ido interpretando yo la poesía de Pablo Neruda, partiendo de una coincidencia con una de mis lecturas más sentidas de estudiante, entre los autores del Siglo de Oro español: Quevedo. En mis manos cayó un día ese libro nerudiano de Viajes ${ }^{2}$, que contiene el famoso "Viaje al corazón de Quevedo", y me llamó la atención la declaración del poeta chileno que consideraba a su «colega» español, sí un «hombre turbulento y temible», según el afirmado cliché, pero también «el más grande de los poetas espirituales de todos los tiempos» ${ }^{3}$.

Esta declaración, que venía de un hombre tan políticamente comprometido y que, en la acepción común, debía ser considerado un convencido «materialista», impulsó mi curiosidad a profundizar en su obra, y más cuando leí el párrafo del mismo "Viaje", donde declaraba:

Quevedo fue para míla roca tumultuosamente corta$\mathrm{da}$, la superficie sobresaliente y cortante sobre un fondo de color de arena, sobre un paisaje histórico que recién me comenzaba a nutrir. Los mismos oscuros dolores que quise vanamente formular, y que tal vez se hicieron en mí extensión y geografía, confusión de origen, palpitación vital para nacer, los
1 Amado Alonso, Poesía y estilo de Pablo Neruda, Buenos Aires, Editorial Sudamericana, 1951 ( $2^{\mathrm{a}} \mathrm{ed}$.)

2 Pablo Neruda, Viajes, Santiago de Chile, Nascimento, 1955.

3

P. Neruda, "Viaje al corazón de Quevedo", ibid., pág. 10. 
4

Ibid., pág. 17

5

P. Neruda, "Puerto Rico Puerto Pobre", Canción de gesta, La Habana, Imprenta Nacional de Cuba, 1960.

6 Cfr. G. Bellini, Quevedo in America (Tre saggi), Milano, Cisalpino-Goliardica, 1974.

7

G. Bellini, Quevedo nella poesia ispano-americana del 1900, Milano, Editrice Viscontea, 1967.

8

P. Neruda, "Con Quevedo en primavera", Jardín de invierno, Buenos Aires, Editorial Losada, 1974.

9

P. Neruda, "Alianza (Sonata)", Residencia en la tierra, en Obras Completas, I, Buenos Aires, Editorial Losada, 1962 ( $2^{\mathrm{a}} \mathrm{ed}$.), y Francisco de Quevedo, "Retrato de Lisi que traía en una sortija", Obras Completas, I: Poesía original, Edición, introducción, bibliografía y notas de José Manuel Blecua, Barcelona, Editorial Planeta, 1963.

10

P. Neruda, "Oda con un lamento", Residencia en la tierra (III), en Obras Completas, cit., I.

11

Cfr. P. Neruda, «Notas» a Viajes, op. cit., p. 201.

12

Cfr. a este propósito $G$. Bellini, "Pablo Neruda fundador de utopías", en Actas del VIII Congreso de la Asociación Internacional de Hispanistas, Madrid, Istmo, 1986, I.

\section{3}

P. Neruda, "A Matilde Urrutia", Cien sonetos de amor, Buenos Aires, Editorial Losada, 1960.

14

P. Neruda, "Infancia y poesía", Obras Completas, l, cit., pág. 31.

Viaje al corazón de Neruda GIUSEPPE BELLINI encontré detrás de España, plateada por los siglos, en lo íntimo de la estructura de Quevedo. Fue entonces mi padre mayor y mi visitador de España. Vi a través de su espectro la grave osamenta, la muerte física, tan arraigada a España. Este gran contemplador de osarios me mostraba lo sepulcral, abriéndose paso entre la materia muerta, con un desprecio imperecedero por lo falso, hasta en la muerte. Le estorbaba el aparato de lo mortal: iba en la muerte derecho a nuestra consumación, a lo que llamó con palabras únicas 'la agricultura de la muerte'. Pero cuanto le rodeaba, la necrología adorativa, la pompa y el sepulturero fueron sus repugnantes enemigos. Fue sacando ropaje de los vivos, su obra fue retirar caretas de los altos enmascarados, para preparar al hombre a la muerte desnuda, donde las apariencias humanas serán más inútiles que la cáscara del fruto caído. Sólo la semilla vuelve a la tierra con el derecho de su desnudez original ${ }^{4}$.

En estas palabras estaba, para mí, el significado profundo del gran poeta, el poeta destinado a sobrevivir en el tiempo, inquietado por esa «agricultura de la muerte», expresión a distancia de tiempo todavía presente en Canción de gesta, donde Neruda afirma que nada podrá nunca silenciarle,

salvo la triste magnitud del tiempo

y su aliada: la muerte con su arado

para la agricultura de los huesos ${ }^{5}$.

Tiempo y muerte. Años después fui profundizando en la presencia de Quevedo en América, en su influencia en los poetas de la Colonia ${ }^{6}$, pero sobre todo en los del siglo $\mathrm{XX}$, especialmente $\mathrm{Neruda}^{7}$, constatando una adhesión continuamente confirmada a través del tiempo, hasta los días finales del gran chileno, como revela en la poesía póstuma el soneto "Con Quevedo en primavera", donde Neruda, ya mortalmente enfermo, viendo que todo en torno a él está floreciendo, se autocontempla desoladamente e implora:

Primavera exterior, no me atormentes, desatando en mis brazos vino y nieve, corola y ramo roto de pesares, dame por hoy el sueño de las hojas nocturnas, la noche en que se encuentran los muertos, los metales, las raíces, y tantas primaveras extinguidas que despiertan en cada primavera 8 .
Lejos está la "familia de oro" de "Alianza (Sonata)", reminiscencia quevedesca en la primera Residencia en la tierra ${ }^{9}$, así como los «dientes y relámpagos» de que resplandece la mujer en "Oda con un lamento", de la segunda Residencia ${ }^{10}$, señal de una preferencia inicial, en el ámbito poético, para el sector amoroso de la poesía de Quevedo. Lecturas que más tarde profundizan en la médula verdadera de la obra del autor del Siglo de Oro. Sabemos que fue ocasional el encuentro y que valió para sustituir la idea «bufonesca, parasatírica» que le habían proporcionado a Neruda «malos textos» $y$ «malas antologías»: el poeta nos cuenta que llegando a Madrid, dio, en una librería de lance de la estación de Atocha, con «un viejo y atormentado libraco", encuadernado en pergamino, que contenía la obra poética de Quevedo y que toda la noche la pasó leyendo su «tesoro»11. Lecturas que luego ampliaría, evidentemente, al resto de la prosa, especialmente a los Sueños.

Toda una trayectoria, una existencia, dominada, por encima de las numerosas construcciones utópicas, proyectadas obstinadamente hacia un futuro feliz para la humanidad ${ }^{12}$, por un solo problema de incontestable magnitud: el de la consunción y la muerte. Una poesía, pues, la de Neruda, de signo fundamentalmente dramático, y por eso de extraordinario interés, drama que ya se abre paso en la concepción de la experiencia amorosa, como aparece en los Veinte poemas de amor y una canción desesperada. No un amor gozoso, sí delirante; la condición feliz será propia de un breve período, que corresponde en la poesía a Los versos del Capitán, y sólo a una parte de ellos, así como estará presente en una sola parte de los Cien sonetos de amor, donde Neruda rivaliza con el Canzoniere de Petrarca, celebrando a Matilde a través de «madererías de amor», como las define ${ }^{13}$, y hay que tener en cuenta lo que significa la madera para el poeta chileno, aroma de la infancia, "elemento natural» de su vida ${ }^{14}$.

En el cuarto grupo de este modernísimo «Canzoniere», «Noche», ya se insinúa el tormento de la ausencia, el temor a la muerte, a la anulación final de la pareja, perspectiva aterradora para quien, como enamorado, piensa más bien en la eternidad. El poeta reacciona entonces refugiándose en el panteísmo: 
Ya no habrá sino todo el aire libre,

las manzanas llevadas por el viento,

el suculento libro en la enramada,

y alli donde respiran los claveles

fundaremos un traje que resista

la eternidad de un beso victorioso $0^{15}$.

Hombre entre los hombres, Neruda nos revela, a lo largo de su poesía, sus más íntimas experiencias acerca del amor. Su concepción de que el corazón del poeta es como una gran alcachofa con hojas para todas las mujeres ${ }^{16}$ indica que su concepción del amor corresponde, durante mucho tiempo, nuevo Casanova ${ }^{17}$, a una relación precaria, pasajera. Cuando escribe los Veinte poemas..., Neruda es un joven que recién se abre al mundo de los afectos. Durante su residencia en Asia, correrá sus aventuras, rechazando «lenocinios» y amor a precio, tendrá una experiencia bastante desaforada y dramática con una mujer birmana, a la que deja por fin con engaño y que, no obstante, sigue añorando siempre, como demuestran los poemas "Tango del viudo" 18 y "Josie Bliss"19.

También en esto Neruda revela su nivel humano, como lo había revelado en el vigésimo de los Veinte poemas..., "Puedo escribir los versos más tristes esta noche» ${ }^{20}$, donde es más bien la soledad el tormento, el amordesamor, saber que la mujer a la que ya no quiere no está en sus brazos. Con una consideración que va mucho má allá del episodio personal: «Es tan corto el amor, y es tan largo el olvido».

Afirmación que confina directamente con la desilusión y que en años más tardos llevará al poeta, en el Memorial de Isla Negra, a rememorar, en un sistema binario, sus amores, las mujeres que sigue ocultando bajo nombres ficticios, Terusa, Rosaura, Josie Bliss, y uno real, Delia (Del Carril), anteriormente su esposa, considerando lo que ellas representaron en un tiempo y lo que ahora son, o podrán ser, con esa melancolía sutil que despierta el recuerdo de pasados amores, cuando al desamor se mezcla el sentido del tiempo que pasa.

Son estos temas los que más inciden en la sensibilidad del lector y que dan dimensión a la poesía nerudiana. Neruda es el intérprete de las angustias del hombre, de sus problemas; un hombre que no es un héroe sino un ser corriente, de dimensión familiar, podría decirse, del que el poeta comparte la condición. Un ser humilde y que, sin embargo, por el sólo hecho de ser hombre, «es más ancho que el mar y que sus islas». Penetrar en él enriquece: «hay que caer en él como en un pozo para salir del fondo / con un ramo de agua secreta, $y$ de verdades sumergidas», afirma en "Alturas de Macchu Pichhu" 21 . Por eso Neruda lo va buscando "A través del confuso esplendor», y encuentra que sólo ha experimentado en el tiempo dolor y vertido sangre.

La experiencia asiática es de signo imborrable, su lección asoma por todas partes en la poesía nerudiana y determina los momentos más profundos de su creación poética. Por eso hay que subrayar siempre el valor de las primeras Residencias en la tierra, no solamente desde el punto de vista de la novedad estilística, sino desde el de la profundidad de la experiencia vivencial y de la orientación espiritual nerudiana. $Y$ hay que hacerlo a pesar de que el poeta, en una época, ha negado que estos poemas fuesen producto de aquella estación imborrable y hasta los ha repudiado, a raíz de su conversión socialista. Pero ya en 1951, al publicar sus Poesías Completas ${ }^{22}$, Neruda incluía en el libro las Residencias, y en 1959, cuando yo estaba reuniendo una antología de sus poemas, me recomendaba que pusiese de ellas «bastantes poemas» ${ }^{23}$.

Se encuentra aquí la raíz de su adhesión a Quevedo, antes de que le conociera realmente a través de su obra. Llama la atención, no solamente el concepto del tiempo ${ }^{24}$, del desgaste que domina las $\operatorname{cosas}^{25}$ y el hombre, sino del concepto de que todo está en poder de la muerte y el hombre es una mínima cosa en el concierto del mundo. Los «ataúdes a vela» que zarpan con «difuntos pálidos, con mujeres de trenzas muertas, / con panaderos blancos como ángeles, / con niñas pensativas casadas con notarios», y suben «el río vertical de los muertos», con velas «hinchadas por el sonido silencioso de la muerte», la cual a todos espera dominando, desde el puerto, "vestida de almirante» ${ }^{26}$, son prueba evidente del impacto profundo del mundo indiano en la sensibilidad nerudiana. Como lo es el espectáculo fúnebre que, en "Entierro en el Este”, pone el poeta frente a la inconsistencia humana: quemado y reducido a ceniza, luego arrojada al agua, nada queda de los aparentemente «tan poderosos viajeros / que hicieron
15

P. Neruda, soneto «C», Cien sonetos de amor, op. cit.

16

P. Neruda, "Infancia y poesía", Obras Completas, I, op. cit., pág. 25.

17

Sobre el rema: G. Bellini, "Amor y erotismo en la poesía de Pablo Neruda", en Actas del Congreso de italianistas, Salamanca, (en prensa).

18

Cfr. P. Neruda, "Tango del viudo", Residencia en la tierra (I), en Obras Completas, cit.

19

P. Neruda, "Tango del viudo", Residencia en la tierra (II), ibidem.

20

P. Neruda, «20», Veinte poemas de amor y una canción desesperada, en Obras Completas, I, cit.

21

P. Neruda, "Alturas de Macchu Picchu: XI", Canto General, ibidem.

22

P. Neruda, Poesías Completas, Buenos Aires, Editorial Losada, 1951.

23

Carta personal desde Santiago de Chile, a 30 de octubre de 1959.

24

P. Neruda, "Vuelve el otoño", Residencia en la tierra (II), en Obras Completas, cit.

25

P. Neruda, "La calle destruida", Residencia en la tierra (II), ibídem.

26

P. Neruda, "Sólo la muerte", Residencia en la tierra (II), ibidem.

Viaje al corazón de Neruda GIUSEPPE BELLINI 
P. Neruda, «Entierro en el Este», Residencia en la tierra (I), ibídem.

\section{8}

P. Neruda, "Aquellas vidas", La luna en el laberinto, de Memorial de Isla Negra, en Obras Completas, II, cit.

\section{9}

P. Neruda, "Vuelve el otoño", Residencia en la tierra (II), en Obras Completas, I, cit.

\section{0}

P. Neruda, "Débil del alba", Residencia en la tierra (I), ibídem.

31

P. Neruda, "Reunión bajo las nuevas banderas", Tercera residencia en la tierra, ibídem.

\section{2}

Luis Aragón, en P. Neruda, Poesías Completas, op. cit., pág. 444.

\section{3}

P. Neruda, "Canto sobre unas ruinas", España en el corazón, en Tercera residencia en la tierra, ibídem.

\section{4}

P. Neruda, "Donde cayó el sediento", Las piedras de Chile, en Obras Completas, cit., II.

\section{5}

P. Neruda, "El gran mantel", Estravagario, ibídem.

\section{6}

"Las guerras", ibídem.

\section{7}

P. Neruda, "Muerte de un periodista", Fin de mundo, Buenos Aires, Editorial Losada, 1969

\section{8}

P. Neruda, "Infancia y poesía", en Obras Completas, I, op. cit., pág. 37.

39

Ibid., págs. 37-38.

Viaje al corazón de Neruda GIUSEPPE BELLINI arder algo sobre las negras aguas, y devoraron / un aliento desaparecido y un licor extremo» ${ }^{27}$.

Aterrador memento mori, lección inolvidable. A distancia de años, en el Memorial de Isla Negra, todavía Neruda tendrá clara la imagen y la lección:

Y si algo vi en mi vida fue una tarde en la India, en las márgenes de un río: arder una mujer de carne y hueso y no sé si era el alma o era el humo lo que del sarcófago salía hasta que no quedó mujer ni fuego ni ataúd ni ceniza: ya era tarde y sólo noche y agua y sombra y río allí permanecieron en la muerte ${ }^{28}$.

En "Reunión bajo las nuevas banderas" despierta el optimismo de Neruda. Renunciando a la autocontemplación y conmiseración de sí mismo en nombre de la solidaridad, sale positivamente de ese «enlutado día» ${ }^{29}$, «día de los desventurados», día «pálido», que asomaba «con un desgarrador olor frío, con sus fuerzas en gris, / sin cascabeles, goteando el alba por todas partes», y que había representado «un naufragio en el vacío, con un alrededor de llanto» ${ }^{30}$. El futuro se le presentaba radiante: «Es la hora / alta de tierra y de perfume», proclamaba, y el renovado corazón del poeta saludaba a los que se habían reunido bajo las "nuevas banderas", "con su flor desbordante, determinada y áurea» ${ }^{31}$.

La realidad fue pronto muy distinta: en España la guerra civil con todos sus desastres - recordemos la violenta protesta nerudiana en España en el corazón, gigantesca introducción a toda la poesía protestataria del siglo $\mathrm{XX}$, según afirmó acertadamente Aragón $\mathrm{n}^{32}, \mathrm{y}$ la tierna imagen de la «fragante novia», víctima inocente del conflicto ${ }^{33}$-; en las minas de su país la explotación del dinero; en América las dictaduras sanguinarias; en todo el mundo los enfrentamientos destructores determinados por dos imperialismos rivales.

Naturalmente Neruda acusaba sólo al imperialismo estadounidense. Su adhesión al mundo comunista era, en cierto sentido, natural, si consideramos la situación de América Latina, pero tuvo un momento difícil cuando Jruschov denunció los delitos de Stalin y al verificarse la disidencia entre la Unión Soviética y China: celebrador de Stalin y de
Mao, pensó entonces, ingenuamente, en justificarse, sin convencer a nadie. La poesía celebrativa anterior y la de justificación, poca en realidad, pertenecen a lo que puede tranquilamente olvidarse de su inmensa creación artística. Son los errores de un ser humano, entre tantos que se equivocaron; lo que no afecta al valor y al significado de la generalidad de su conducta y de su poesía.

Hay una constante en Neruda y en su creación artística que todo lo rescata, y es la preocupación por el hombre. No un hombre triunfante -éste pertenece solamente al sueño utópico-, sino el ser explotado y vejado: el pobre caminante que caía y moría sediento al lado del camino, en Las piedras de Chile ${ }^{34}$; el que sufría el hambre y para el cual el poeta soñaba, en Estravagario, mesas planetarias, «platos como la luna / en donde todos almorcemos» ${ }^{35}$; el desdichado aplastado por un tanque en Praga, durante la invasión soviética; la niña, «Muñeca del Asia quemada / por los aéreos asesinos» ${ }^{36}$. Un siglo de horribles crímenes que le hacía divisar un fin aterrador:

\section{Preparémonos a morir \\ en mandíbulas maquinarias, \\ preparemos piernas, espaldas, \\ meditaciones y caderas, \\ codos, rodillas, entusiasmo, \\ párpados y sabiduría \\ serán tragados, triturados \\ $y$ digeridos por un tanque ${ }^{37}$.}

Es el problema humano el que da valor permanente a la poesía nerudiana, el problema del hombre acosado por la injusticia, la explotación y la muerte. Falta sobre todo la fraternidad, «maravillosa acción de la vida» ${ }^{38}$, y por este motivo Neruda se consideraba afortunado, pues la había encontrado siempre y la consideraba el don más grande que había recibido, porque

Conocer el amor de los que amamos es el fuego que alimenta la vida. Pero sentir el cariño de los que no conocemos, de los desconocidos que están velando nuestro sueño y nuestra soledad, nuestros peligros y nuestros desfallecimientos, es una sensación aún más grande y más bella porque extiende nuestro ser y abarca todas las vidas $5^{39}$.

El recuerdo iba a un episodio de la infancia. En el capítulo autobiográfico del Canto 
General, donde alude a la solidaridad encontrada cuando la persecución de González Videla, vuelve al tema, consciente ahora de lo que él personalmente representa, en la hora difícil, para su patria. Es una familia humilde que le acoge y le esconde, pero toda la tierra chilena es la que le protege:

Tierra nocturna, a mi ventana

llegabas con tus labios,

para que yo durmiera dulcemente

como cayendo sobre miles de hojas,

de estación a estación, de nido a nido,

de rama en rama, hasta quedar de pronto

dormido como un muerto en tus raíces ${ }^{40}$.

El sentido del límite no abandona nunca a Neruda. En las Odas elementales, celebrando las cosas minúsculas de lo creado, animales, insectos, piedras, mientras afirma el valor de la creación, el significado de la sencillez, de la pura belleza, se abre paso también la nota del dolor humano. Frente a los elementos imperturbables y eternos, el océano, las piedras, el tiempo, se encuentra todo un universo destinado a la destrucción, que ni la bondad ni la belleza pueden preservar. Lo que lleva siempre a una problemática ante todo personal, en donde se refleja la de toda la humanidad. En la "Oda a unas flores amarillas", el espectáculo del mar, la belleza de las flores sencillas que han nacido en la playa, devuelve a Neruda al tema del polvo, al memento bíblico, sólo consolado por un incierto panteísmo:

\section{Ni aire, ni fuego, ni agua \\ sino \\ tierra, \\ sólo tierra \\ seremos \\ y tal vez \\ unas flores amarillas ${ }^{41}$.}

El sentido del fin y del polvo explica la preocupación casi desesperada de Neruda por el hombre. A pesar de las numerosas afirmaciones acerca del advenimiento inevitable del día feliz, la visión nerudiana del mundo sigue siendo sustancialmente la de "Débil del alba» y el día que asoma sobre la tierra es siempre el «día de los desventurados». Sobre este panorama se afirma una única realidad: la muerte. Las novedades formales no ocultan el proble- ma, ya planteado por Neruda en su «Viaje al corazón de Quevedo»:

Hay una sola enfermedad que mata, y ésa es la vida. Hay un solo paso, y es el camino hacia la muerte. Hay una manera sola de gasto y de mortaja, es el paso arrastrador del tiempo que nos conduce. Nos conduce ęadónde? Si al nacer empezamos a morir, si cada día nos acerca a un límite determinado, si la vida misma es una etapa patética de la muerte, si el mismo minuto de brotar avanza hacia el desgaste del cual la hora final es sólo la culminación de ese transcurrir, ¿no integramos la muerte en nuestra cotidiana existencia, no somos parte perpetua de la muerte, no somos lo más audaz, lo que ya salió de la muerte? ¿No es lo más mortal, lo más viviente, por su mismo misterio? ?2 $^{2}$

Estas consideraciones acercan Neruda no solamente a Quevedo, sino a la concepción náhuatl de la máquina del universo, como la representa Octavio Paz: la vida vuelve, con la muerte, a integrarse en él. Pero en Neruda la armonía universal desaparece, sustituida por la ineludible muerte-germinación. La vida brota de la muerte y a ella regresa; el tiempo todo lo arrastra y nos lleva, ‘adónde? El drama nerudiano está todo en esta pregunta sin contestación y que su querido Quevedo había resuelto a través de la fe.

Estravagario es en la producción nerudiana un libro de gran relevancia en cuanto a problemática. Sin renunciar nunca a su compromiso, el poeta reivindica el derecho a tratar los temas que le agitan dentro. El clima elegíaco, ya tan presente en las Residencias, el Canto General y las Odas, penetra hasta el canto del amor, y desemboca en Neruda en la desolación y el temor por su propio acabar en la tierra.

Son motivos que dan a la poesía nerudiana esa profundidad que sobrecoge: la inmensidad del océano, que nos obliga a darnos cuenta «de la poca cosa que somos» ${ }^{43}$; la eternidad del tiempo y su indiferencia, reloj sin prisa ${ }^{44}$; la muerte moderadora de soberbias; el drama de un partir sin destino cierto; el abandono de lo que queda del ser creado en el mundo sensible, trajes vacíos y el orgullo ${ }^{45}$. Inquietantes son los interrogativos en torno al porqué y por cuánto tiempo vive el hombre, por cuánto tiempo muere, qué quiere decir «para siempre», qué nos espera después de la muerte $\mathrm{e}^{46}$.
40

P. Neruda, "X. El fugitivo", Canto General, ibidem.

41

P. Neruda, "Oda a unas flores amarillas", Tercer libro de las odas, ibídem,

42

P. Neruda, "Viaje al corazón de Quevedo", Viajes, op. cit., pág. 18.

43

P. Neruda, "Desconocidos en la orilla", Estravagario, en Obras Completas, II, op. cit.

44

P. Neruda, "Ya se fue la ciudad", Estravagario, ibídem.

45

Ibidem.

46

P. Neruda, "Y cuánto vive?", ibidem.
Viaje al corazón de Neruda GIUSEPPE BELLINI 
P. Neruda, "Yo volveré", Las piedras de Chile, op. cit.

48

P. Neruda, "Los nacimientos", Plenos poderes, en Obras Completas, II, cit.

49

P. Neruda en carta personal de 1964.

50

P. Neruda, "Canto", Fin de mundo, op. cit.

51

P. Neruda, carta personal desde Isla Negra, con fecha 10 de septiembre de 1969.

52

P. Neruda, "La puerta", Fin de mundo, op. cit.

53

P. Neruda, "LXXXXVII: Dicen y vivirán", La espada encendida, Buenos Aires, Editorial Losada, 1970 ,

\section{4}

P. Neruda, «XV||», Las piedras del cielo, Buenos Aires, Editorial Losada, 1970

55

Ibidem.

56

P. Neruda, «XXX», ibidem.

57

P. Neruda, carta personal desde París con fecha 4 de julio, de 1972.

Viaje al corazón de Neruda GIUSEPPE BELLIN
Neruda, como bien sabemos, no llega a ningún resultado positivo y repudia las soluciones que ofrecen las religiones, pero no se resigna. La solución panteísta por la que se inclina en el último de los Cien sonetos de amor, es sólo un recurso transitorio. Y tanto que el problema vuelve a dominar los poemarios sucesivos, desde Canción de gesta hasta Las piedras de Chile. En este último libro el problema personal del poeta se hace transparente: la invitación, cuando ya no sea, es a buscarle entre aguas y piedras en una problemática transformación:

$$
\begin{aligned}
& \text { aquí volveré a ser el movimiento } \\
& \text { del agua, de } \\
& \text { su corazón salvaje, } \\
& \text { aquí estaré perdido y encontrado: } \\
& \text { aquí seré tal vez piedra y silencio.47 }
\end{aligned}
$$

En los Cantos ceremoniales también domina la nota reflexiva y preocupada, la problemática existencial que da el tono al nuevo libro. Clima que es propio también de Plenos poderes. La poesía, para Neruda, es ahora sólo invitación a meditar. El mensaje de esperanza que en las intenciones era razón primera de su poesía, queda sumergido por la problemática que se cifra en la constatación de que «Nunca recordaremos haber muerto»48. O sea, que nunca recordaremos haber vivido. De aquí procede la melancolía que penetra toda la poesía última de Neruda, desde el Memorial de Isla Negra, donde la novedad se afirma sobre una veta constantemente autobiográfica, en los temas que desde siempre han preocupado al poeta. El Memorial es, como declaró Neruda, un "canto personal» en contraposición aparente con el Canto General, destinado a cobrar importancia en la historia de su poesía ${ }^{49}$.

Lo que siempre preocupa al poeta es la condición y el destino del hombre y su propio destino. El tema del tiempo y de la muerte domina también en Las manos del día, donde la tragedia de Viet Nam propone nuevamente a la conciencia del autor los términos trágicos de la vida, sitiada por el mal y destinada a la destrucción. El clima otoñal, entendido no como un replegarse sobre sí mismo, sino en el significado del prevalecer de un acento preocupado se agudiza en Fin de mundo, uno de los libros poéticos más profundos de Neruda. Insidia constante son la maldad y la muerte.
La problemática nerudiana vuelve como nunca a proponer los eternos interrogativos que aquejan al hombre y el poeta acaba por reconocerse cómplice de la humanidad malvada, con sus «hermanos asesinos» ${ }^{50}$. Neruda afirmó que Fin de mundo era un libro «amargo, una especie de pesadilla acerca de la crueldad y la maldad del siglo $X X{ }^{51}$, pero por encima de la angustia y de cualquier comprobación del mal, reafirmaba una vez más la conciencia de tener una misión irrenunciable, a pesar de todas las desilusiones: el deber de afirmar al «hombre infinito»: «Mi deber es vivir, morir, vivir» ${ }^{52}$, es decir tomar parte activa en la vida del hombre y reconstruir para él la esperanza en el futuro.

Atormentado por este compromiso y la constatación del prevalecer del mal, entre la celebración de las cosas, el canto del amor y los documentos escalofriantes de la ruina y la muerte, dramáticamente en suspenso frente al más allá, a pesar de las pequeñas soluciones siempre insatisfactorias, sediento de permanencia, Neruda prosigue su investigaciónconfesión en cada una de sus colecciones poéticas, con el único paréntesis de La espada encendida, poema de la vida que surge desde la muerte: «Desde toda la muerte llegamos al comienzo de la vida» ${ }^{53}$.

También en Las piedras del cielo vuelven estos problemas: las piedras, desde las miserables de los ríos hasta las más preciosas, ofrecen una lección de eternidad negada al hombre, que en su fragilidad «se desploma y deshace su materia, / su palabra y su voz se desmenuzan» ${ }^{54}$. El tiempo corre sin dañar las piedras que, a diferencia de los humanos no conocen el macabro proceso de la pudrición: "La piedra intacta ignora / el pasajero paso del gusano ${ }^{55}$. Son acentos que nos conducen nuevamente a Quevedo, pero de pronto Neruda reacciona inaugurando una nueva perspectiva de permanencia:
en este punto o puerto o parto o muerte
piedra seremos, noche sin banderas,
amor inmóvil, fulgor infinito,
luz de la eternidad, fuego enterrado,
orgullo condenado a su energía,
única estrella que nos pertenece ${ }^{56}$.

Es de nuevo una solución transitoria. En Geografía infructuosa, que Neruda afirmó como uno de sus libros más maduros ${ }^{57}$, el 
poeta vuelve a contemplar su propio límite, aquejado ahora por la enfermedad, la mecánica del mundo que nos transforma en números, la condena a repetir gestos siempre iguales, que nos llevan a un único fin, mientras la vida renace continuamente. La profundidad del pensamiento nerudiano se encuentra en estos acentos y hasta en el sentido de fracaso que le asalta, por haber sobrevivido con sus ideales a un mundo que ha proseguido obstinadamente hacia la ruina. Se explica así el ulterior acentuarse del sentido del polvo, en la perspectiva de una partida última entre la indiferencia general:

Sí, no se altera nada pero talvez se altera algo, una brizna, el aire, la vida, o en fin, todo, y cuando ya cambió todo ba cambiado, se ba ido uno también, con nombre y buesos ${ }^{58}$.

No cabe duda, el avanzar de la edad, el acoso de la enfermedad, que en pocos meses debía llevarle a la tumba, las esperanzas desilusionadas, la conciencia lúcida de su fin próximo, acentuaron aún más el tono meta- físico de la poesía nerudiana, al que aporta su contribución relevante la poesía última publicada póstumamente. El destino no debía evitar a Neruda, por pocos días, el espectáculo trágico del derrumbe de todas sus ilusiones. Concluía así, con el acento dramático que domina en su poesía, también la vida del poeta, sin que él hubiera podido dar solución a ninguno de sus problemas, ni realizar las perspectivas felices que obstinádamente había ido soñando. Su obra es el documento vivo y emocionante de una búsqueda angustiosa y de una dedicación que, por encima de toda posición partidaria, por encima de toda crítica legítima y serena, afirma su sinceridad.

Sobre todo en este sentido me parece lícito interpretar la poesía de Pablo Neruda, sin pretender por esto ocultar sus claudicaciones, afirmando empero su imperecedero significado de documento de un hombre y gran poeta que en sí ha vivido y expresado las dudas y los sueños de cada individuo, interpretando las tragedias de nuestro tiempo. Por estos motivos su poesía sigue hablando al lector.
58

P. Neruda, "Pero talvez", Geografía infructuosa, Buenos Aires, Editorial Losada, 1972. 